\title{
Pulmonary trunk to ascending aorta ratio and reference values for diameters of pulmonary arteries and main bronchi in healthy adults
}

\author{
Büşra Pirinç ${ }^{1}$ (D), Zeliha Fazlıoğulları ${ }^{1}$ (D), Mustafa Koplay ${ }^{2}$ (D), Ahmet Kağan Karabulut ${ }^{1}$ (D), \\ Nadire Ünver Doğan ${ }^{1}$ \\ ${ }^{1}$ Department of Anatomy, School of Medicine, Selçuk University, Konya, Turkey \\ ${ }^{2}$ Department of Radiology, School of Medicine, Selçuk University, Konya, Turkey
}

\begin{abstract}
Objectives: The ratio of the diameter of pulmonary trunk (PT) to the diameter of the ascending aorta (AA) is used to evaluate cardiopulmonary diseases. Different values have been reported for the normal value of PT:AA ratio (to be less than 0.9, 1 or 1.4). In this study, we aimed to investigate the diameters of the PT, right (RPA) and left pulmonary artery (LPA), AA, right $(\mathrm{RMB})$ and left main bronchus $\mathrm{LMB}$ ) using multidetector computed tomography (MDCT) and to determine reference values for PT:AA according to age and sex in normal healthy adults.
\end{abstract}

Methods: Thoracic CT images of 200 individuals, (103 males, 97 females; age 18-89 years), without cardiopulmonary pathology and surgery, were retrospectively evaluated using MDCT. Diameters of PT, RPA, LPA, AA were measured at the level of the pulmonary artery bifurcationand PT:AA ratio was calculated.

Results: The mean diameters of PT, AA, RPA, LPA, RMB, LMB were found as $2.7 \pm 0.51 \mathrm{~cm}, 3.25 \pm 0.63 \mathrm{~cm}, 1.98 \pm 0.46 \mathrm{~cm}$, $1.81 \pm 0.43 \mathrm{~cm}, 1.73 \pm 0.35 \mathrm{~cm}$, and $1.66 \pm 0.55 \mathrm{~cm}$, respectively. The mean value of PT:AA ratio was $0.84 \pm 0.18 \mathrm{~cm}$ in males and $0.86 \pm 0.13 \mathrm{~cm}$ in females.

Conclusion: Determining the normal values of related measurements will contribute to diagnosis and treatment of cardiopulmonary diseases.

Keywords: ascending aorta; MDCT; pulmonary trunk

Anatomy 2020;14(1):22-28 C2020 Turkish Society of Anatomy and Clinical Anatomy (TSACA)

\section{Introduction}

The aorta is the main artery in the human body. Originating from the left ventricle of the heart, it is divided into the ascending aorta (AA), aortic arch, and descending aorta. ${ }^{[1]}$

Pulmonary trunk (PT) carries venous blood from the right ventricle of the heart to the lungs. ${ }^{[2]} \mathrm{PT}$ runs upwards on the left side of the AA and bifurcates into the right and left pulmonary artery (RPA, LPA) beneath the aortic arch and anterior to the left main bronchus (LMB). ${ }^{[1]}$ The RPA passes horizontally to the right being posterior to the AA and superior vena cava and inferior to the carina. The LPA runs inferiorly and posteriorly before leaving the pericardium under the aortic arch..$^{[3]}$ At the hilum, the $\mathrm{RPA}$ is located superior and posterior to the right main bronchus (RMB) and superior pulmonary vein. When the LPA enters the hilum, the superior pulmonary vein is at its anterior and the LMB at its posterior side. ${ }^{[1]}$

The ratio of the diameter of the PT to the diameter of the AA, referred as PT:AA ratio, is used to evaluate cardiopulmonary diseases. It is a useful indicator for to determine diseases with pulmonary artery enlargement; espe-

This study was presented as an oral presentation at the IV International Academic Research Congress, October 30 - November 3, 2018, Antalya, Turkey. 
cially for diagnosis of pulmonary arterial hypertension $(\mathrm{PAH})$ and estimation of frequent exacerbations of chronic obstructive pulmonary disease (COPD). ${ }^{[4,5]}$ In addition, PT:AA ratio can be a predictive of underlying diseases, as well as may serve as an indicator for prognosis of the patient. ${ }^{[6]}$ The normal value of PT:AA ratio have been reported in a wide range in recent studies (as less than 0.9, 1 or 1.4$).^{[4,5,7-10]}$

The trachea bifurcates into RMB and LMB at the level of the fourth thoracic vertebra. ${ }^{[2]}$ Knowing the exact localization of this bifurcation is important for anesthesiologists and thoracic surgeons. ${ }^{[1]}$ Detailed knowledge of the morphology of the tracheobronchial tree, particularly knowing the diameters of the bronchi, helps to optimize surgical procedures such as intubation, reconstruction of the airway tree, and improving medical equipments such as double-lumen endobronchial tube. ${ }^{[12]}$ The normal reference value of morphometric variables differ among various population groups and sometimes even among various ethnic groups within the same population. $^{[11]}$

In this study, we aimed to investigate the diameters of PT, RPA, LPA, AA, RPB, LPB using multidetector computed tomography (MDCT) and additionally to determine normal reference values for PT:AA ratio in healthy adults according to age and sex. We believe that these measurements will be used as decisive data for possible lung diseases.

\section{Materials and Methods}

Thoracic CT images of 200 adults (103 males, 97 females, min age: 18, max age: 89 ) without any cardiopulmonary pathologies and recent surgeries at thoracic region were retrospectively evaluated with MDCT. The past medical history revealed that MDCT was requested from these patients with a preliminary diagnosis of pulmonary nodule. Patients were divided into three groups according to age by taking the most-frequentlyseen/onset age of lung diseases into account as $40^{[13]}$ and geriatric age as 60 (we consider people over 60 years as older adults, as advocated by the World Health Organization) Accordingly those between the ages of 18-39 were determined as Group 1, 20-40 as Group 2, more than 61 as Group 3 (Table 1).

Scans were performed with a 256-slice multidetector computed tomographic scanner (Siemens Somatom Flash, Erlangen, Germany). Imaging parameters were as follows: $\mathrm{Kv}=120 ; \mathrm{mA}=160$; rotation time $=0.5 \mathrm{~s}$; collimation $=64 \times 0.625 ; \mathrm{FOV}=220 \mathrm{~mm}$. Images were analyzed retrospectively on a workstation by the same radi-
Table 1

Distribution of individuals by age and gender.

\begin{tabular}{lcccc} 
& \multicolumn{3}{c}{ Age groups } \\
\cline { 2 - 4 } & $\begin{array}{l}\text { Group 1 } \\
(\mathbf{1 8 - 3 9 )}\end{array}$ & $\begin{array}{c}\text { Group 2 } \\
\mathbf{( 4 0 - 6 0 )}\end{array}$ & $\begin{array}{c}\text { Group 3 } \\
(\mathbf{2 6 1 )}\end{array}$ & Total \\
\cline { 1 - 4 } Females & 30 & 26 & 41 & 97 \\
\hline Males & 26 & 38 & 39 & 103 \\
\hline
\end{tabular}

ologist (Snygo Via, Siemens, Munich, Germany). This single-center retrospective study was approved by the local institutional review board with a waiver of the requirement for written, informed consent. Ethical approval was obtained from the Non-Intervention Clinical Research Ethics Committee of Medical Faculty (approval number 2018/128).

The PT and AA were evaluated on axial sections at the level of the bifurcation point of pulmonary arteries (ideally where both the RPA and LPA appear). Diameters of PT and AA were measured where they have the widest diameter (Figures 1 and 2). They usually had their widest diameter on the axial section which was close to the bifurcation of $\mathrm{PT} .^{[5,6,14-17]} \mathrm{PT}$ :AA ratio was calculated relying on these measurements.

The diameters of RPA and LPA were evaluated on axial sections taken at the level of the bifurcation of pulmonary arteries (Figure 3). ${ }^{[18]}$

The maximum distance between the lateral and medial walls of the RMB and LMB was measured on the coronal sections obtained close to carina (Figure 4). ${ }^{[1]}$

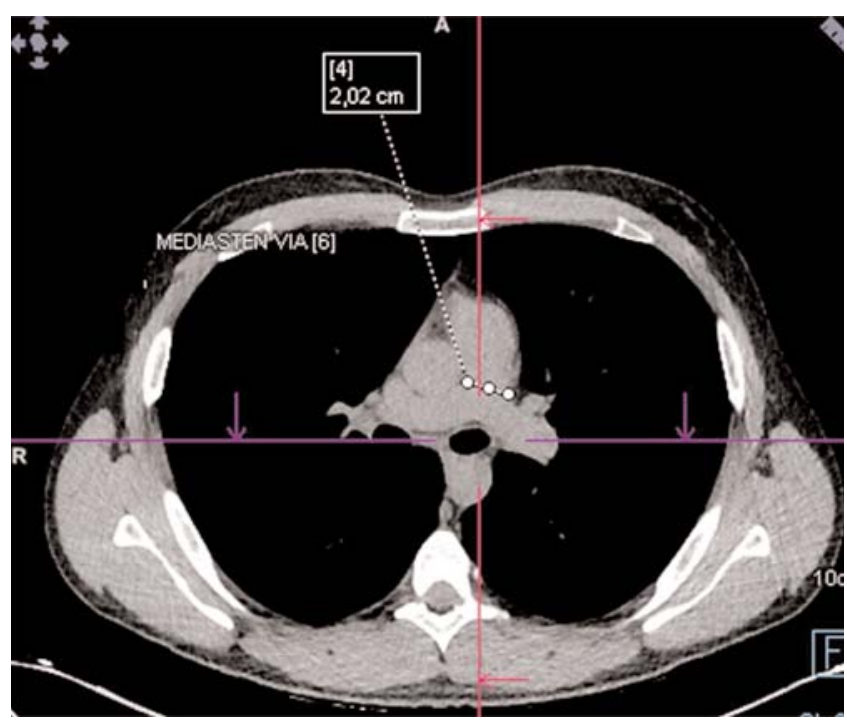

Figure 1. Measurement of PT diameter (axial section). 


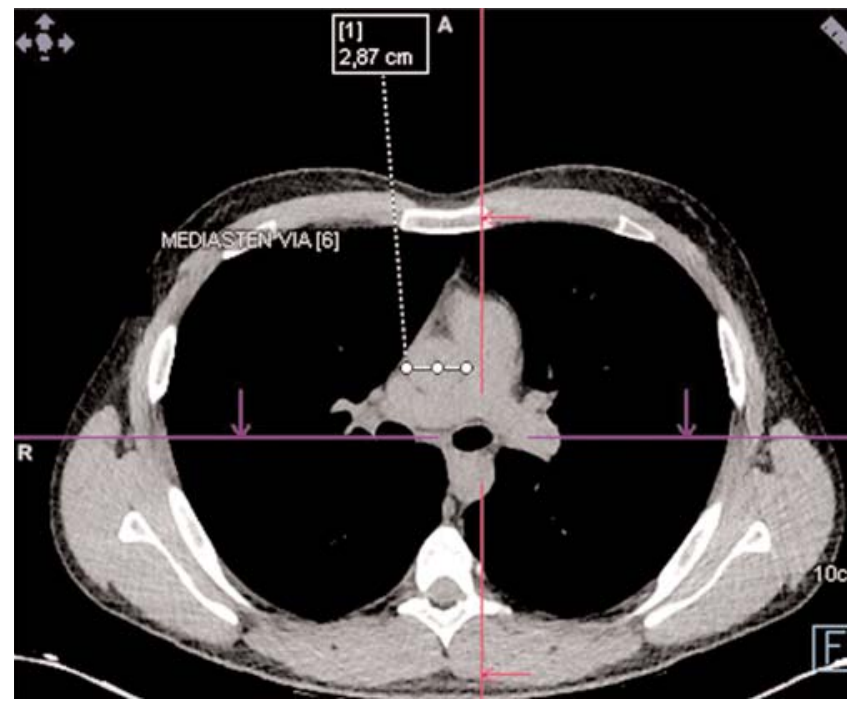

Figure 2. Measurement of AA diameter (axial section).

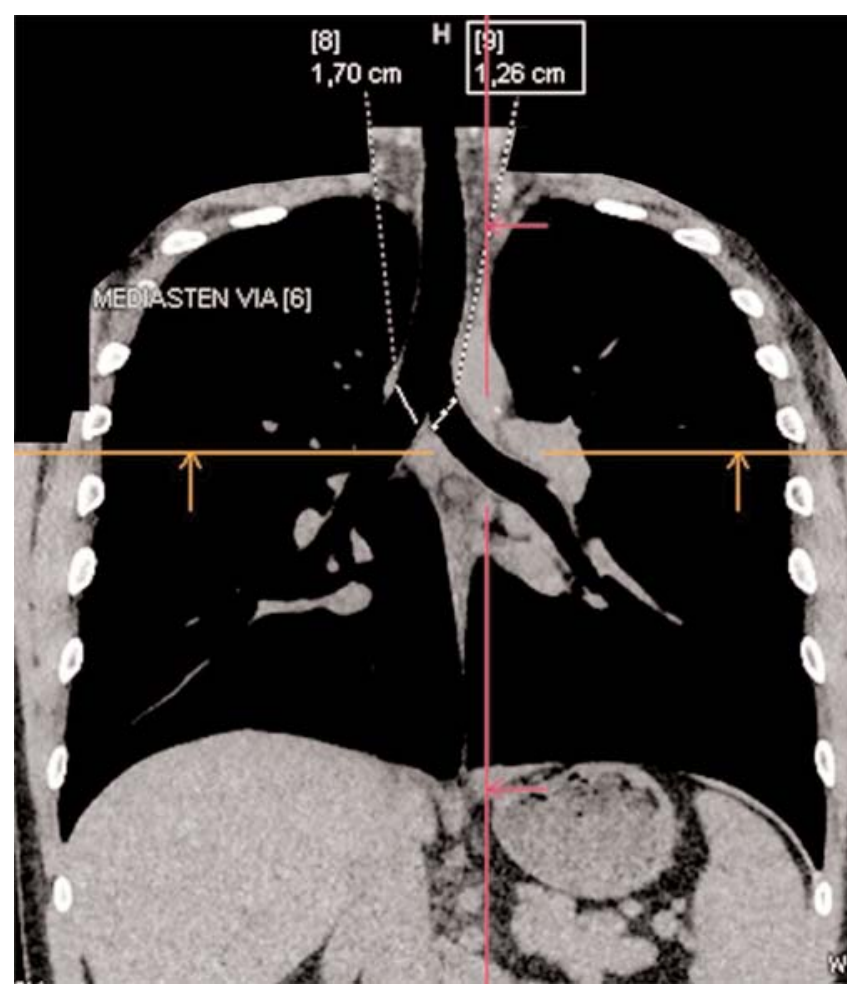

Figure 4. Diameters of RMB and LMB (coronal section).

All statistics were carried out using SPSS Statistics for Windows (Version 22, Chicago, IL, USA). Normality and homogeneity of variances were checked from the parametric test assumptions before applying the one-way ANOVA and independent samples t-test. The data were expressed as mean \pm standard deviation

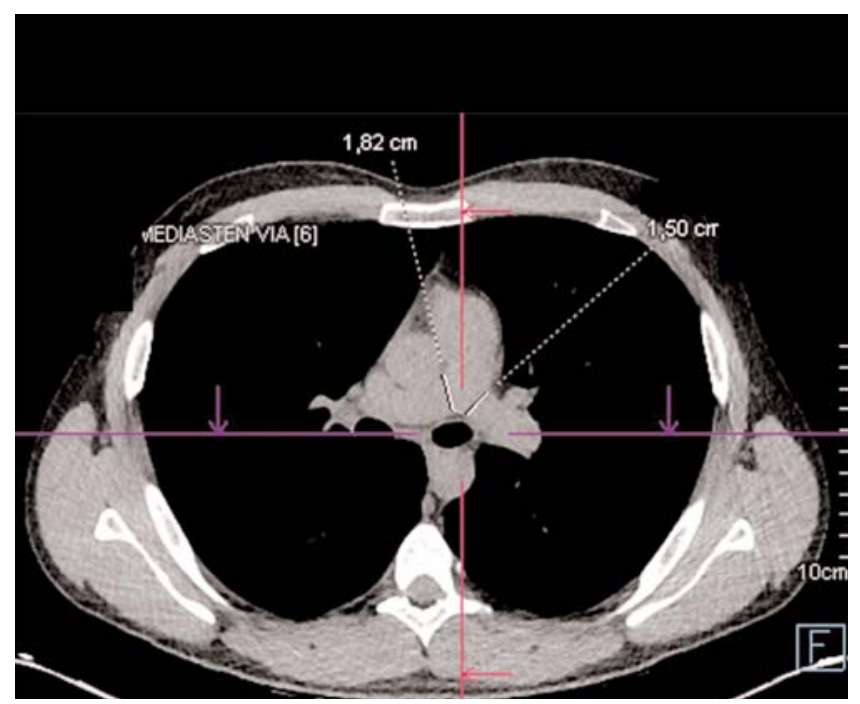

Figure 3. Diameters of RPA and LPA (axial section).

(SD), minimum and maximum values. One-way ANOVA was used to compare the significance between different groups; $\mathrm{p}<0.05$ was considered statistically significant.

\section{Results}

The diameters of PT, AA and LPA were significantly larger in Group 3 compared to the other two groups $(\mathrm{p}<0.05)$. There was no statistically significant difference between Group 1 and 2 ( $>>0.05)$. The PT:AA ratio was higher in Group 1 compared to Group $2(\mathrm{p}<0.05)$.

The mean value of PT:AA ratio was $0.84 \pm 0.18 \mathrm{~cm}$ in males and $0.86 \pm 0.13 \mathrm{~cm}$ in females. This value was minimum $0.44 \mathrm{~cm}$, maximum $1.41 \mathrm{~cm}$ among all individuals. The mean PT:AA ratio was significantly higher in Group 1 when compared to Group $2(\mathrm{p}<0.05)$. The mean PT:AA ratio of Group 3 was not statistically significant when compared to the other two groups $(\mathrm{p}>0.05)$.

The diameter of RPA was significantly larger in Group 3 than Group $1(\mathrm{p}<0.05)$. The mean diameter of RPA in Group 2 showed no statistically significant difference compared to the other two groups ( $\mathrm{p}>0.05)$.

When RMB and LMB diameters were compared according to age groups, the mean differences between groups were not statistically significant $(\mathrm{p}>0.05)$ (Table 2 ).

The PT:AA ratio was found to be $0.84 \pm 0.18 \mathrm{~cm}$ and $0.86 \pm 0.13 \mathrm{~cm}$ in males and females, respectively. When PT, AA, LPA diameters and PT:AA ratio were compared according to gender, the mean differences between groups were not statistically significant ( $p>0.05)$. However, RPA, 
Table 2

The minimum, maximum and mean diameters of PT, AA, RPA, LPA, RMB, LMB and PT:AA ratio in healthy adults according to age.

\begin{tabular}{|c|c|c|c|c|c|c|}
\hline \multirow[b]{2}{*}{ Diameters } & \multicolumn{3}{|c|}{ Min-Max (cm) } & \multicolumn{3}{|c|}{ Mean $\pm S D(\mathrm{~cm})$} \\
\hline & Group 1 & Group 2 & Group 3 & Group 1 & Group 2 & Group 3 \\
\hline PT & $1.32-4.07$ & $1.56-3.74$ & $1.87-4.2$ & $2.58 \pm 0.52$ & $2.53 \pm 0.46$ & $2.92 \pm 0.47$ \\
\hline AA & $1.52-4.25$ & $1.89-4.45$ & $2.39-4.85$ & $2.93 \pm 0.64$ & $3.15 \pm 0.49$ & $3.4 \pm 0.46$ \\
\hline PT:AA & $0.57-1.41$ & $0.44-1.24$ & $0.6-1.4$ & $0.9 \pm 0.18$ & $0.81 \pm 0.15$ & $0.85 \pm 0.14$ \\
\hline RPA & $0.71-2.62$ & $1.35-2.7$ & $1.16-3.56$ & $1.8 \pm 0.44$ & $1.92 \pm 0.34$ & $2.15 \pm 0.48$ \\
\hline LPA & $0.83-2.54$ & $0.91-2.61$ & $1.15-3.1$ & $1.7 \pm 0.4$ & $1.67 \pm 0.37$ & $1.99 \pm 0.43$ \\
\hline RMB & $0.87-2.37$ & $1.17-2.27$ & $1.01-2.57$ & $1.73 \pm 0.29$ & $1.68 \pm 0.28$ & $1.73 \pm 0.3$ \\
\hline LMB & $0.77-2.49$ & $1.11-2.4$ & $0.91-2.3$ & $1.55 \pm 0.34$ & $1.63 \pm 0.28$ & $1.65 \pm 0.26$ \\
\hline
\end{tabular}

AA: ascending aorta; LMB: left main bronchus; LPA: left pulmonary artery; PT: pulmonary trunk; RMB: right main bronchus; RPA: right pulmonary artery.

$\mathrm{RMB}$ and $\mathrm{LMB}$ diameters were significantly higher in males than females $(\mathrm{p}<0.05)$ (Table 3).

\section{Discussion}

Pulmonary arterial hypertension is characterized with increased pulmonary vascular resistance and may lead to right heart failure and eventually to death. Increase in pulmonary vascular resistance resulting in higher pulmonary artery pressure and vessel wall tension causes enlargement of the PT. ${ }^{[19]}$

Enlargement of the PT is frequently recognized in patients with severe PAH. It has also been reported that there is an association between defective pulmonary activity and arterial diameter, especially with respect to the PT rather than the aorta ${ }^{[6]}$ A dilated PT may be seen on radiography or echocardiography; however, a CT or magnetic resonance imaging of the chest enables more correct measurements. ${ }^{[2]} \mathrm{CT}$ is a non-invasive method which can be employed for assessing both intrinsic pulmonary and intrathoracic vascular diseases. ${ }^{[1,22]}$ Chest and cardiac CT have become more widely accessible and they are frequently ordered for diagnosing pulmonary, cardiac and vascular diseases in clinical practice. ${ }^{[23]}$

COPD is a highly prevalent dysfunction and an important cause of mortality worldwide. It is characterized by progressive, permanent airway obstruction which is associated with a chronic inflammatory course in the airways and pulmonary parenchyma. PAH occurs in serious COPD cases due to various reasons, such as hypoxic vasoconstriction, pulmonary hyperinflation with increased intrathoracic pressure, or loss of pulmonary vascular capacity due to parenchymal devastating. ${ }^{[21]}$

The PT enlargement is simply measured noninvasively and is due to a variety of conditions, including $\mathrm{PAH}^{[20]}$ The PT:AA ratio is used as a tool to evaluate the dilatation of the pulmonary arterial segments since dilation is not

Table 3

The minimum, maximum and mean diameters of PT, AA, RPA, LPA, RMB, LMB and PT:AA ratio in healthy adult according to gender.

\begin{tabular}{lcccc} 
& \multicolumn{2}{c}{ Min-Max $(\mathbf{c m})$} & \multicolumn{2}{c}{ Mean \pm SD $(\mathbf{c m})$} \\
Diameters & Females & Males & Females & Males \\
\hline PT & $1.32-4.2$ & $1.56-4.19$ & $2.68 \pm 0.53$ & $3.72 \pm 0.5$ \\
\hline AA & $1.52-4.85$ & $1.91-4.75$ & $3.16 \pm 0.61$ & $0.28 \pm 0.53$ \\
\hline PT:AA & $0.62-1.16$ & $0.44-1.41$ & $0.86 \pm 0.13$ & $2.84 \pm 0.18$ \\
\hline RPA & $0.71-3.2$ & $1.06-3.56$ & $1.91 \pm 0.46$ & $1.04 \pm 0.44$ \\
\hline LPA & $0.83-3.1$ & $0.91-2.87$ & $1.81 \pm 0.46$ & 1.39 \\
\hline RMB & $0.87-2.57$ & $1.18-2.55$ & $1.61 \pm 0.28$ & $1.81 \pm 0.26$ \\
\hline LMB & $0.77-2.27$ & $1.03-2.49$ & $1.49 \pm 0.25$ & $1.74 \pm 0.28$ \\
\hline
\end{tabular}

AA: ascending aorta; LMB: left main bronchus; LPA: left pulmonary artery; PT: pulmonary trunk; RMB: right main bronchus; RPA: right pulmonary artery. 
Table 4

Comparison of PT and AA diameters and PT:AA ratio with previously published studies.

\begin{tabular}{|c|c|c|c|c|c|c|c|c|c|c|c|c|}
\hline \multicolumn{2}{|c|}{ Method } & \multirow[t]{3}{*}{ Population } & \multirow[t]{3}{*}{$\begin{array}{l}\text { Age } \\
\text { range } \\
\text { (year) }\end{array}$} & \multicolumn{3}{|c|}{ PT } & \multicolumn{3}{|c|}{ AA } & \multicolumn{3}{|c|}{ PT:AA } \\
\hline \multirow[t]{2}{*}{ MRI } & \multirow[t]{2}{*}{ Pellicori et al. ${ }^{[14]}$} & & & \multicolumn{3}{|c|}{ Range: $2.51-2.88 \mathrm{~cm}$} & \multicolumn{3}{|c|}{ Range: $3.39-3.43 \mathrm{~cm}$} & \multicolumn{3}{|c|}{ Mean: 0.9} \\
\hline & & & & $\begin{array}{c}\text { Females } \\
(\mathrm{cm})\end{array}$ & $\begin{array}{l}\text { Males } \\
(\mathrm{cm})\end{array}$ & $\begin{array}{l}\text { Mean } \\
(\mathrm{cm})\end{array}$ & $\begin{array}{l}\text { Females } \\
(\mathrm{cm})\end{array}$ & $\begin{array}{l}\text { Males } \\
(\mathrm{cm})\end{array}$ & $\begin{array}{l}\text { Mean } \\
(\mathrm{cm})\end{array}$ & Females & Males & Mean \\
\hline \multirow[t]{2}{*}{ CT } & Edwards et al...$^{[15]}$ & & $11-90$ & 2.64 & 2.77 & 2.72 & & & & & & \\
\hline & Truong et al. ${ }^{[23]}$ & American & $\geq 18$ & & & 2.63 & & & 3.17 & & & 0.84 \\
\hline \multirow[t]{4}{*}{ MDCT } & Compton et al...$^{16]}$ & Canadian & $0-18$ & & & & & & & & & 1.09 \\
\hline & Lee et al. ${ }^{[6]}$ & Korean & $>20$ & 2.58 & 2.65 & 2.59 & 2.96 & 3.16 & - & 0.88 & 0.85 & 0.87 \\
\hline & $\begin{array}{l}\text { Caro-Dominguez } \\
\text { et al. }{ }^{[17]}\end{array}$ & Canadian & $1-17$ & 1.71 & 1.72 & 1.71 & - & - & - & 1.1 & 1.13 & 1.11 \\
\hline & Present study & Turkish & $18-89$ & $2.68 \pm 0.53$ & $2.70 \pm 0.5$ & $2.7 \pm 0.51$ & $3.16 \pm 0.61$ & $3.31 \pm 0.63$ & $3.23 \pm 0.57$ & $0.86 \pm 0.13$ & $0.84 \pm 0.18$ & $0.85 \pm 0.16$ \\
\hline
\end{tabular}

AA: ascending aorta; CT: computed tomography; MDCT: multidetector computed tomography study; MRI: magnetic resonance imaging; PT: pulmonary trunk.

seen in AA although PAH causes selective dilation of the PT and its main branches. ${ }^{[17]}$ Different values have been reported regarding the normal range of $\mathrm{PT}$ :AA ratio in various studies (to be less than $0.9,1$ or 1.4 ). ${ }^{[4,5,7-10]}$ An elevated PT:AA ratio was important since it was associated with an increased risk of all-cause mortality $(>0.9){ }^{[4]}$ The mean PT:AA ratio was found higher in females than in males for all age groups, but this ratio found to decrease with increasing age in both genders ${ }^{[6]}$ Our study revelaed the PT:AA ratio in a range of $0.44-1.41 \mathrm{~cm}$, showing significant differences according to age.

In adults, the maximum limit of the PT:AA ratio is assumed to be 1 and if this ratio is more than 1, it is considered to be an indicator of PAH. But this ratio shows differences in the pediatric cases. In a study performed on healthy children under 18 years of age, it was reported that the PT:AA was not affected by sex. ${ }^{[16]}$

The diameters of PT, AA, LMB, RMB and PT:AA ratio in different populations have been investigated by using different methods (Tables 4 and 5). PT diameter found in our study was similar with previous studies. ${ }^{[6,1,1,1,23]}$ The diameter of PT was significantly higher in male than in female as reported by some previous studies, ${ }^{[0,15]}$ but the results of Caro-Dominguez et al., ${ }^{[17]}$ and our study showed no statistically significant difference between males and females. When compared with the results of the previous studies, ${ }^{[6,23]}$ the diameter of AA found in our study was found similar. Lee et al., ${ }^{[6]}$ reported the diameter of AA as significantly higher in males than in females but our study showed no significant difference. ${ }^{[6,1,23]}$ The results of our study revealed that diameters of RMB and LMB were higher than in previous studies. ${ }^{[1,24]}$ These diameters were found higher in male, in both our study and in earlier studies. ${ }^{[1,24]}$ The body mass index, body surface area and lifestyle differences may be the reason of these differences. ${ }^{[6]}$

Tracheal and bronchial diseases are rare and have a sneaky progress. Serious obstruction findings occur when $75 \%$ of trachea or bronchial lumen is blocked. Symptoms

Table 5

Comparison of RMB and LMB diameters with previously published studies.

\begin{tabular}{|c|c|c|c|c|c|c|c|c|c|c|c|c|c|}
\hline \multirow[b]{2}{*}{ Method } & & \multirow[b]{2}{*}{ Population } & \multirow[b]{2}{*}{$\begin{array}{l}\text { Age range } \\
\text { (year) }\end{array}$} & \multicolumn{5}{|c|}{ RMB } & \multicolumn{5}{|c|}{ LMB } \\
\hline & & & & \multicolumn{2}{|c|}{$\begin{array}{l}\text { Females } \\
(\mathrm{cm})\end{array}$} & \multicolumn{2}{|c|}{$\begin{array}{l}\text { Males } \\
(\mathrm{cm})\end{array}$} & \multirow{2}{*}{$\begin{array}{c}\begin{array}{c}\text { Mean } \\
(\mathbf{c m})\end{array} \\
1.33\end{array}$} & \multicolumn{2}{|c|}{$\begin{array}{l}\text { Females } \\
(\mathrm{cm})\end{array}$} & \multicolumn{2}{|c|}{$\begin{array}{c}\text { Males } \\
(\mathrm{cm})\end{array}$} & $\begin{array}{c}\text { Mean } \\
(\mathrm{cm})\end{array}$ \\
\hline Multi-slice spiral CT & Mi et al. ${ }^{[11]}$ & Chinese & $18-90$ & \multicolumn{2}{|c|}{1.23} & \multicolumn{2}{|c|}{1.41} & & \multicolumn{2}{|c|}{1.13} & \multicolumn{2}{|c|}{1.31} & 1.23 \\
\hline Spiral CT & Kim et al. ${ }^{[24]}$ & Asian & $19-80$ & $\begin{array}{l}\mathrm{AP} \\
1.32\end{array}$ & $\begin{array}{c}\text { TR } \\
1.18 \\
\end{array}$ & $\begin{array}{c}\text { AP } \\
1.53\end{array}$ & $\begin{array}{c}\text { TR } \\
1.51\end{array}$ & & $\begin{array}{l}\text { AP } \\
1.03\end{array}$ & $\begin{array}{l}\text { TR } \\
9.9\end{array}$ & $\begin{array}{l}\text { AP } \\
1.27\end{array}$ & $\begin{array}{c}\text { TR } \\
1.31\end{array}$ & \\
\hline MDCT & Present study & Turkish & $18-89$ & 1.65 & $=0.39$ & $1.71=$ & 0.29 & $1.71 \pm 0.2$ & 1.56 & .72 & 1.74 & $=0.27$ & $1.62 \pm 0.3$ \\
\hline
\end{tabular}

AP: anteroposterior; CT: computed tomography; LMB: left main bronchus; MDCT: multidetector computed tomography; RMB: right main bronchus; TR: transverse. 
may be nonspecific and it may be difficult to diagnose because the findings may be misinterpreted. For this reason, MDCT which is a non-invasive method is often preferred for routine screening and management of the patients. ${ }^{[25,26]}$ Studies on morphometric evaluation of airways are limited. The accumulation of medical or environmental inhalation materials in the lungs makes it necessary to know the normal range of diameters of major airways. $^{[27,28]}$

We defined a set of normal range of age and gender specific PT, AA, RPA, LPA, LMB, RMB diameters and PT:AA ratio by MDCT in 200 healthy adults with no predisposing factors for cardiopulmonary diseases, such as PAH, COPD. We suggest that knowing these parameters can provide physicians to assess current cardiopulmonary status of patients. Reference values of RMB and LMB diameters can especially be valuable to radiologists, anesthesiologists, otolaryngologists and thoracic surgeons. Knowledge of diameters of LMB and RMB is important for interpreting situations such as recurrent infections, hemoptysis and malignancy and for applying procedures such as bronchoscopy.

\section{Conclusion}

Due to the anatomically complicated shape and axis of the PT and its branches, measurements of the PT at various positions may be dissonant and misleading to accurately predict PAH or COPD exacerbation. Therefore, knowing the diameters of the PT and its branches may be useful for following-up the patients with PAH and COPD.

\section{Author Contributions}

BP: project development, data collection, data analysis, writing text, $\mathrm{ZF}$ : project development, data analysis, final check of the manuscript, MK: data collection, data analysis, AKK: final check of the manuscript, NUD: final check of the manuscript.

\section{References}

1. Tubbs RS, Shoja MM, Loukas M (eds). Bergman's comprehensive encyclopedia of human anatomic variation. Hocoken (NJ): John Wiley \& Sons, Inc; 2016.

2. Frechette E, Deslauriers J. Surgical anatomy of the bronchial tree and pulmonary artery. Semin Thorac Cardiovasc Surg 2006;18:7784.

3. Ugalde P, Miro S, Frechette E, Deslauriers J. Correlative anatomy for thoracic inlet; glottis and subglottis; trachea, carina, and main bronchi; lobes, fissures, and segments; hilum and pulmonary vascular system; bronchial arteries and lymphatics. Thorac Surg Clin 2007; 17:639-59.

4. Nakanishi R, Rana JS, Shalev A, Gransar H, Hayes SW, Labounty TM, Dey D, Miranda-Peats R, Thomson LEJ, Friedman JD, Abidov A, Min JK, Berman DS. Mortality risk as a function of the ratio of pulmonary trunk to ascending aorta diameter in patients with suspected coronary artery disease. Am J Cardiol 2013;111:1259-63.

5. Dou S, Zheng C, Ji X, Wang W, Xie M, Cui L, Xiao W. Co-existence of COPD and bronchiectasis: a risk factor for a high ratio of main pulmonary artery to aorta diameter (PA:A) from computed tomography in COPD patients. Int J Chron Obstruct Pulmon Dis 2018;13:675-81.

6. Lee SH, Kim YJ, Lee HJ, Kim HY, Kang YA, Park MS, Kim YS, Kim SK, Chang J, Jung JY. Comparison of CT-determined pulmonary artery diameter, aortic diameter, and their ratio in healthy and diverse clinical conditions. PLoS One 2015;10:e0126646.

7. Wells JM, Washko GR, Han MK, Abbas N, Nath H, Mamary AJ, Regan E, Bailey WC, Martinez FJ, Westfall E, Beaty TH, CurranEverett D, Curtis JL, Hokanson JE, Lynch DA, Make BJ, Crapo JD, Silverman EK, Bowler RP, Dransfield MT; COPDGene Investigators; ECLIPSE Study Investigators. Pulmonary arterial enlargement and acute exacerbations of COPD. N Engl J Med 2012;367:913-21.

8. Rho JY, Lynch DA, Suh YJ, Nah JW, Zach JA, Schroeder JD, Cox CW, Bowler RP, Fenster BE, Dransfield MT, Wells JM, Hokanson JE, Curran-Everett D, Williams A, Han MK, Crapo JD, Silverman EK. CT measurements of central pulmonary vasculature as predictors of severe exacerbation in COPD. Medicine (Baltimore) 2018;97: e9542.

9. Iyer AS, Wells JM, Vishin S, Bhatt SP, Wille KM, Dransfield MT. CT scan-measured pulmonary artery to aorta ratio and echocardiography for detecting pulmonary hypertension in severe COPD. Chest 2014;145:824-32.

10. de-Torres JP, Ezponda A, Alcaide AB, Campo A, Berto J, Gonzalez J, Zulueta JJ, Casanova C, Rodriguez-Delgado LE, Celli BR, Bastarrika G. Pulmonary arterial enlargement predicts long-term survival in COPD patients. PLoS One 2018;13:e0195640.

11. Mi W, Zhang C, Wang H, Cao J, Li C, Yang L, Guo F, Wang X, Yang T. Measurement and analysis of the tracheobronchial tree in Chinese population using computed tomography. PLoS One 2015; 10:e0123177.

12. Hautmann H, Gamarra F, Henke M, Diehm S, Huber RM. High frequency jet ventilation in interventional fiberoptic bronchoscopy. Anesth Analg 2000;90:1436-40.

13. Buist AS, McBurnie MA, Vollmer WM, Gillespie S, Burney P, Mannino DM, Menezes AMB, Sullivan SD, Lee TA, Weiss KB, Jensen RL, Marks GB, Gulsvik A, Nizankowska-Mogilnicka E; BOLD Collaborative Research Group. International variation in the prevalence of COPD (The BOLD Study): a population-based prevalence study. Lancet 2007;370:741-50.

14. Pellicori P, Urbinati A, Zhang J, Joseph AC, Costanzo P, Lukaschuk E, Capucci A, Cleland JGF, Clark AL. Clinical and prognostic relationships of pulmonary artery to aorta diameter ratio in patients with heart failure: a cardiac magnetic resonance imaging study. Clin Cardiol 2018;41:20-7.

15. Edwards PM, Bull RK, Coulden R. CT measurement of main pulmonary artery diameter. Br J Radiol 1998;71:1018-20.

16. Compton GL, Florence J, MacDonald C, Yoo SJ, Humpl T, Manson D. pulmonary artery-to-ascending aorta diameter ratio in healthy children on MDCT. AJR Am J Roentgenol 2015;205:13225.

17. Caro-Dominguez P, Compton G, Humpl T, Manson DE. Pulmonary arterial hypertension in children: diagnosis using ratio of main pulmonary artery to ascending aorta diameter as determined by multi-detector computed tomography. Pediatr Radiol 2016;46:137883. 
18. Sugimoto K, Nakazato K, Sakamoto N, Yamaki T, Kunii H, Yoshihisa A, Suzuki H, Saitoh S, Takeishi Y. Pulmonary artery diameter predicts lung injury after balloon pulmonary angioplasty in patients with chronic thromboembolic pulmonary hypertension. Int Heart J 2017;58:584-8.

19. Tonelli AR, Johnson S, Alkukhun L, Yadav R, Dweik RA. Changes in main pulmonary artery diameter during follow-up have prognostic implications in pulmonary arterial hypertension. Respirology 2017;22:1649-55.

20. Raymond TE, Khabbaza JE, Yadav R, Tonelli AR. Significance of main pulmonary artery dilation on imaging studies. Ann Am Thorac Soc 2014;11:1623-32.

21. Chung KS, Kim YS, Kim SK, Kim HY, Lee SM, Seo JB, Oh YM, Jung JY, Lee SD; Korean Obstructive Lung Disease Study Group. Functional and prognostic implications of the main pulmonary artery diameter to aorta diameter ratio from chest computed tomography in Korean COPD patients. PLoS One 2016;11:e0154584.

22. Ando K, Kuraishi H, Nagaoka T, Tsutsumi T, Hoshika Y, Kimura $\mathrm{T}$, Ienaga H, Morio Y, Takahashi K. Potential role of CT metrics in chronic obstructive pulmonary disease with pulmonary hypertension. Lung 2015;193:911-8.

ORCID ID:

B. Pirinç 0000-0002-6927-1306; Z. Fazlıoğulları 0000-0002-5103-090X; M. Koplay 000-0001-7513-4968; A. K. Karabulut 0000-0002-9635-8829; N. Ünver Doğan 0000-0001-5696-5547

deomed。
23. Truong QA, Bhatia HS, Szymonifka J, Zhou Q, Lavender Z, Waxman AB, Semigran MJ, Malhotra R. A four-tier classification system of pulmonary artery metrics on computed tomography for the diagnosis and prognosis of pulmonary hypertension. J Cardiovasc Comput Tomogr 2018;12:60-6.

24. Kim D, Son JS, Ko S, Jeong W, Lim H. Measurements of the length and diameter of main bronchi on three-dimensional images in Asian adult patients in comparison with the height of patients. J Cardiothorac Vasc Anesth 2014;28:890-5.

25. Javidan-Nejad C. MDCT of trachea and main bronchi. Thorac Surg Clin 2010;20:65-84.

26. Boiselle PM, Ernst A. State-of-the-art imaging of the central airways. Respiration 2003;70:383-94.

27. Sauret V, Halson PM, Brown W, Fleming JS, Bailey AG. Study of the three-dimensional geometry of the central conducting airways in man using computed tomographic (CT) images. J Anat 2002;200: 123-34.

28. Montaudon M, Desbarats P, Berger P, Dietrich G, Marthan R, Laurent F. Assessment of bronchial wall thickness and lumen diameter in human adults using multi-detector computed tomography: comparison with theoretical models. J Anat 2007;211:579-88.

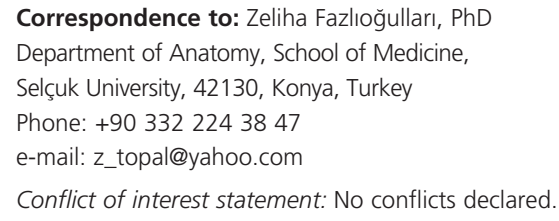

Conflict of interest statement: No conflicts declared.

This is an open access article distributed under the terms of the Creative Commons Attribution-NonCommercial-NoDerivs 3.0 Unported (CC BY-NCND3.0) Licence (http://creativecommons.org/licenses/by-nc-nd/3.0/) which permits unrestricted noncommercial use, distribution, and reproduction in any medium, provided the original work is properly cited. Please cite this article as: Pirinç B, Fazlığulları Z, Koplay M, Karabulut AK, Ünver Doğan N. Pulmonary trunk to ascending aorta ratio and reference values for diameters of pulmonary arteries and main bronchi in healthy adults. Anatomy 2020;14(1):22-28. 